\title{
Morphological Change of Dhaka City Over a Period of 55 Years: A Case Study of Two Wards
}

\author{
Bayes Ahmed* \\ Muhammad Rakibul Hasan Raj** \\ Dr. K. M. Maniruzzaman ${ }^{* *}$
}

\begin{abstract}
Dhaka City has undergone radical changes in its physical form, not only by territorial expansion, but also through internal physical transformations over the last decades. These have created entirely new kinds of fabric. With these changes, the elements of urban form have changed. Plots and open spaces have been transformed into building areas, open squares into car parks, low land and water bodies into reclaimed built-up lands etc. This research has its general interest in the morphologic change of Dhaka City. It focuses on the spatial dynamics of urban growth of Dhaka over the last 55 years from 1952-2007. In the research, the transformation of urban form has been examined through space syntax. The aim behind using this technique is to describe aspects of relationships between the morphological structure of man-made environments and social structures and events. To conduct this research, Wards 49 and 72 of Dhaka City Corporation were selected as the study areas, of which Ward 72 is an indigenous and Ward 49 is a planned type of settlement. Being a planned residential area, the syntactic measures from this morphological analysis are showing quite unchanged and high values in all phases for Ward 49 and the physical characteristics of Ward 72 (Old Dhaka) still represent the past. The syntactic values are found to be higher for Ward 72 and than Ward 49. Higher values indicate that the street network is highly connective among each other. Time affects differently the layout of cities and the architecture of buildings. Of the many human creations, street systems are among the most resistant to change. This has been emphasized in this study, thereby facilitating the comparison of urban layouts across space and time. The interpretation of history in the light of quantitative accounts, as demonstrated in this study, will be of value to urban planners and urban designers for the future planning of modern Dhaka City.
\end{abstract}

\section{Introduction}

Dhaka, the capital of Bangladesh, well known as city of fine muslin, mosques and rickshaws, has a fairly long history of evolution (Taifoor, 1956:43). Dhaka with the passage of time, testifies different faces of history. Now-a-days Dhaka is the most densely populated and rapidly growing city in the third world countries. With its growth, Dhaka has been a showcase for almost every urban problem imaginable.

Like many other cities in the world, modern Dhaka is also the outcome of spontaneous rapid growth without any prior or systematic planning. As the growth of population in Dhaka is taking place at an exceptionally high rate, it has become one of the most populous Mega Cities in the world. In the process of urbanization, the physical characteristics of Dhaka City are gradually changing as open spaces and water bodies are converted into built up areas.

The growth and development of Dhaka can be categorized into six periods, e.g. the pre-Mughal period (1205-1610), the Mughal period (1620-1757), the East India Company period (1758-1858), the British colonial period (1858-1947), the Pakistan period (1947-1971) and the Bangladesh period (from 1971). As society radically changed after British colonial period, Dhaka City underwent drastic changes over the past decades (Dani, 1962:74).

\footnotetext{
* Erasmus Mundus M.Sc. Program in Geospatial Technologies (Continue), Email: bayesahmed@gmail.com

** Graduate student in MDS, East West University, Bangladesh, Email: rakib121@ gmail.com

*** Professor, Department of Urban and Regional Planning,, Bangladesh University of Engineering and Technology (BUET), Dhaka, Email: mzaman@urp.buet.ac.bd
} 
Dhaka City has undergone radical changes in its physical form, not only in its vast territorial expansion, but also through internal physical transformations over the last decades. These have created entirely new kinds of fabric. With these changes in urban form, the elements of urban form have changed. Plots and open spaces have been transformed into building areas, open squares into car parks, low land and water bodies into reclaimed built-up lands etc. This new urban fabric is to be analyzed to understand the changes that have led to its creation. This research has been conducted with an objective of studying the transformation of urban form of Dhaka City over the last 55 years $(1952-2007)$.

\section{Methodology of the Research}

\section{Selection of the Study Area}

For the purpose of carrying out the research and to attain the objective, Wards 49 and 72 have been chosen as the study areas. Ward 72 represents an area that grew in the Pre-Mughal period (Ferdous, 2007:36); whereas Ward 49 is Dhanmondi residential area that was developed as a planned residential area after 1955 (Hashem, 2001:15). Ward is the smallest electoral unit of urban areas in Bangladesh.

\section{Analysis and Interpretation}

The morphological structure has been examined through the use of space syntax method for this research. The aim behind the technique is to describe different aspects of relationships between the morphological structure of man-made environments and social structures and events. Thus space syntax offers a theory and method for investigating society-space relations (Hillier and Hanson, 1984:7). The main theoretical argument is that settlement patterns originate in the social life of the user. Accordingly, the analysis of the spatial patterns of settlements can lead to knowledge about the social norms of societies.

The analytical method is based on the transformation of plans into graphs and the quantifying of the spatial qualities of nodes using mathematical formulae. Such a method offers a simple objective procedure for describing, comparing and interpreting settlements. A number of characteristics make this method a powerful research tool. First, it provides a simple, analysable, and realistic spatial model of a settlement. Secondly, it entails analysis of the elements of a city as related parts of a system. Thirdly, it gives quantitative values to elements and provides statistical and graphical comparisons within the system. Finally, its computations provide values that allow systems of different sizes to be compared (Kubat, 1999:30). Apart from the diagrammatic representation of plans, the analytical procedures of space syntax offer a variety of mathematical measurements that quantify various attributes: integration, connectivity, control and intelligibility values of spatial patterns (Nilufar, 1997:38). The plans of settlements are represented graphically and compared in terms of their patterns of continuous open space in order to analyse the patterns of the urban layouts syntactically. That is why, space syntax method has been chosen for this research.

The morphological analysis is carried out at six different stages in the city's growth considering only the boundary of Ward, by using the maps of 1952-2007 from secondary sources. The axial map of six different periods is used for syntactic analysis, where the highest and the lowest ranges of global integration value $(\mathrm{R}=\mathrm{n})$ is shown in different bands of same colour. The base maps and axial maps are prepared using maps from various sources (maps of 1952, 1973, 1987, 1995 and 2001 are collected from Survey of Bangladesh and for 2007, images from Google Earth are used for all the Wards).

\section{Physical Growth of Dhaka City}

Historically, the development of Dhaka city started from the southern part, that is, the present "old town" (Pre-Mughal period), then the extension continued toward the west and the north (Mughal 
and British period). During Pakistan period, the development advanced primarily toward the north and it continued rapidly and in an unplanned way toward all sides of the city. Figure 1 shows the changing pattern of Dhaka City and its population over different time periods, which eventually influenced the form of the city.

The growth of Dhaka from 1949-1989 followed the limits that were determined by the Mughals (towards north up to Tongi, up to Mirpur in north-west and up to Postogola in south-east). However, the growth caused many low lands to be filled up and all the low lying areas on the eastern and western sides came under occupation. With the rise of population pressure, the high lands spreading towards the north came to be occupied. No serious efforts has been undertaken to create a planned city and Dhaka has now been growing by its own demand (Nilufar, 1997).

\section{Ward 49: A Detailed Morphological Analysis}

Dhanmondi Residential Area (DRA) is one of the high-class residential areas in Dhaka city (Figure 2). The area (Ward 49) was planned and developed in the early fifties to provide residential accommodation for high and higher middle income groups of population in Dhaka city (Mamun, 1993:57).
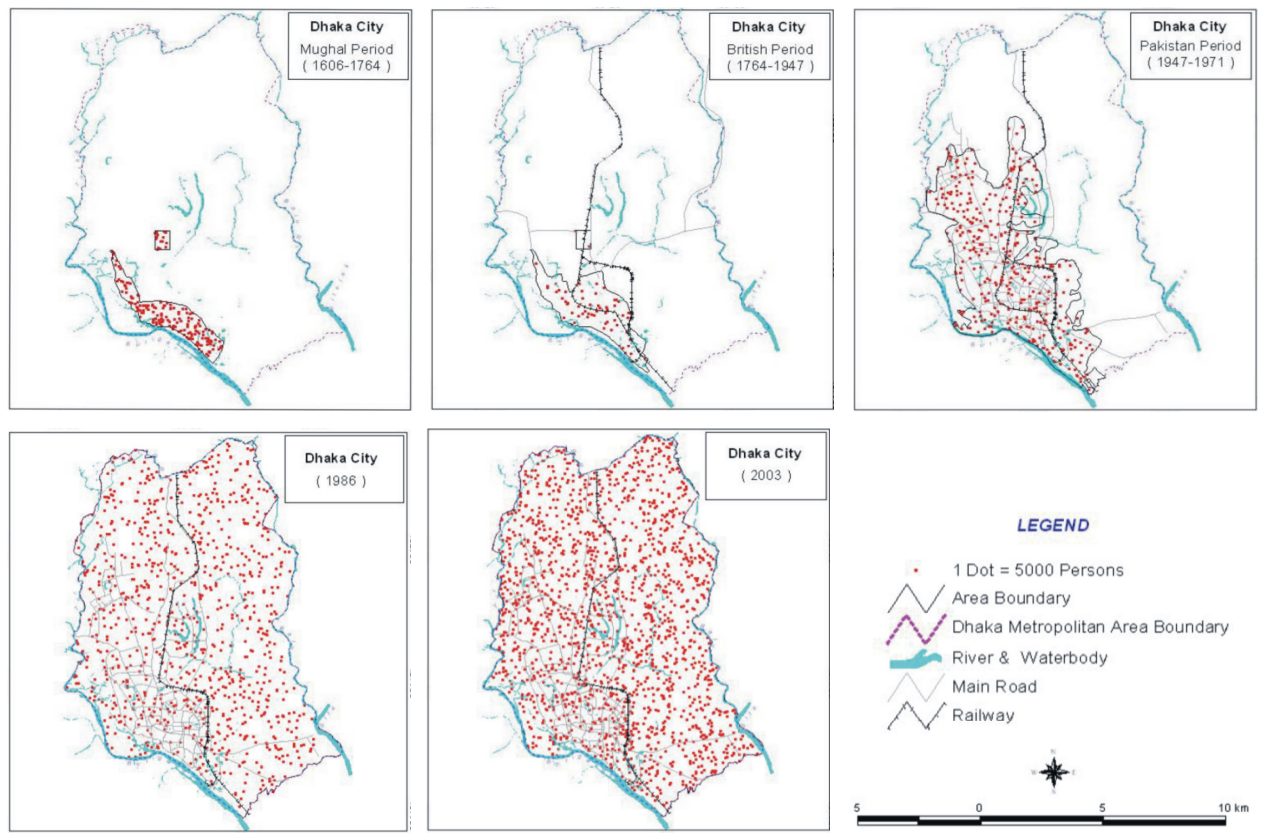

Source: GIS division, Bangladesh Centre for Advanced Studies

Fig. 1: Changing patterns of Dhaka City and its population

The area was designed with large plots, wide roads and good environment, within five kilometers from the Central Business District (CBD) of Dhaka City. After liberation in 1971, the characteristics of the residential area were being changed and the area was gradually being invaded by non-residential uses like commercial and professional offices, private hospitals and clinics, community centers, educational institutions (private schools, colleges and universities) etc.

\section{Morphological Transformation of DRA}

Global Integration Core: The integration core of a city is mainly formed with the highest integrated axial lines. Integration core generally concentrated in the heart of the commercial and 
ceremonial centre (Nilufar, 1997:45). It can be said that in DRA, the integration core follows mainly the commercial activities, and in case of the second highest values, it basically includes the educational, official and other purposes (Figure 3).
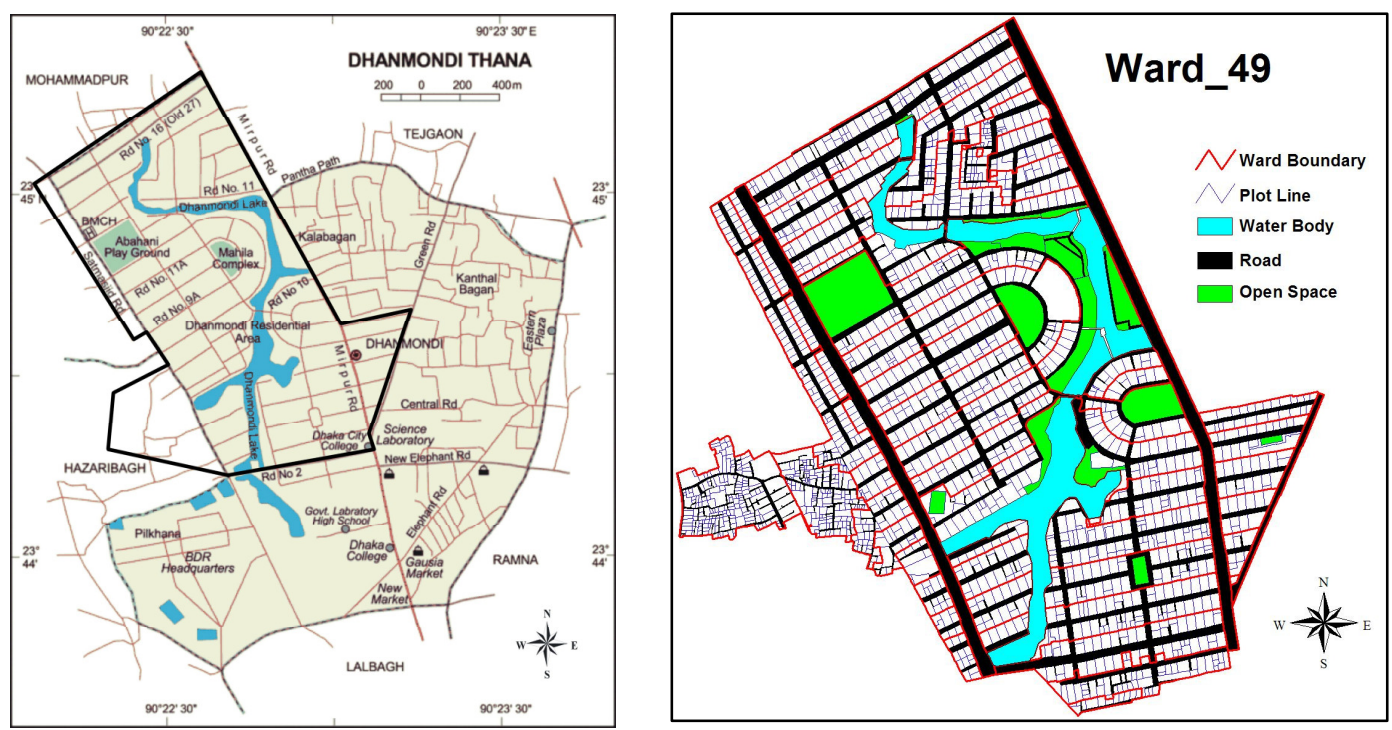

Source: http://www.bangladesh.gov.bd/maps/images/dhaka/DhanmondiT.gif and DCC, 2006

Fig. 2: Map of Dhanmondi Thana and Ward 49

Connectivity: Connectivity $(\mathrm{CN})$ of a space literally means how many spaces intersect with it (Nilufar, 1997:40). The most connected roads are Mirpur Road and Satmasjid Road, kept constant in all phases except 1952. And later the connector road, which passes through the Roads 7A-15A, becomes the highest connected roads (Figure 4).

Intelligibility: According to the space syntax theory, not only the local and global characteristics of urban systems are important issues, but also the interaction between them and the correspondence between the local and global configuration of space is also significant. Intelligibility of an urban system is the degree of correlation between global and local properties of each line in the system. The stronger the correlation, the more we can infer the global position of a space from its directly observable local connections (Nilufar, 1997:41).

It is observed that the global and local correlation (Rn-R3) is very high, static and the tangent of slope is also very steep (Table 01). This indicates strong relationship between the two measures. Moreover, the correlation is almost same in all periods. But the correlation of Rn-CN is a bit lower than Rn-R3. It states that the connectivity pattern of road network in between the global and local streets is slightly deteriorating. In connectivity analysis, it is seen that the local streets are less connected than the global ones.

\section{Summary of Syntactic Analysis of Ward 49}

The syntactic analysis of Ward 49 (DRA) is summarized below:

a) The integration core lies in the commercial zone, like Satmasjid Road and Mirpur Road.

b) The segment numbers are almost unchanged except year, 1952.

c) Global roads are more integrated / accessible, while local roads are much more segregated / inaccessible.

d) Global roads have high connectivity and control values than the local ones. 
e) Locally important roads get less importance to the local inhabitants irrespective to the global measures.

f) The global and local correlation (Rn-R3 and Rn-CN) is high, steady and the tangent of slope is also very steep.

Table 1: Correlation value of Global and Local Measures of Ward 49

\begin{tabular}{|c|c|l|c|l|}
\hline \multirow{2}{*}{ Time Period } & $\begin{array}{c}\mathrm{R} \text { of } \\
\text { Rn-R3/ } \\
\text { Intelligibility }\end{array}$ & \multicolumn{1}{|c|}{ Equation } & $\begin{array}{c}\mathrm{R} \text { of } \\
\text { Rn-CN/ } \\
\text { Intelligibility }\end{array}$ & \multicolumn{1}{|c|}{ Equation } \\
\hline 1952 & 0.8956 & $\begin{array}{l}\mathrm{y}=2.552 \mathrm{x}-0.8897 \\
\mathrm{R}^{2}=0.8021\end{array}$ & 0.7715 & $\begin{array}{l}\mathrm{y}=3.637 \mathrm{x}-1.1012 \\
\mathrm{R}^{2}=0.5953\end{array}$ \\
\hline 1973 & 0.8616 & $\begin{array}{l}\mathrm{y}=2.5777 \mathrm{x}-1.4015 \\
\mathrm{R}^{2}=0.7423\end{array}$ & 0.6663 & $\begin{array}{l}\mathrm{y}=5.9574 \mathrm{x}-4.8272 \\
\mathrm{R}^{2}=0.4439\end{array}$ \\
\hline 1987 & 0.8281 & $\begin{array}{l}\mathrm{y}=2.4972 \mathrm{x}-1.088 \\
\mathrm{R}^{2}=0.6858\end{array}$ & 0.6143 & $\begin{array}{l}\mathrm{y}=5.5076 \mathrm{x}-3.6441 \\
\mathrm{R}^{2}=0.3774\end{array}$ \\
\hline 1995 & 0.8372 & $\begin{array}{l}\mathrm{y}=2.3591 \mathrm{x}-0.9181 \\
\mathrm{R}^{2}=0.7009\end{array}$ & 0.5769 & $\begin{array}{l}\mathrm{y}=5.1805 \mathrm{x}-3.3998 \\
\mathrm{R}^{2}=0.3329\end{array}$ \\
\hline 2001 & 0.7903 & $\begin{array}{l}\mathrm{y}=2.3291 \mathrm{x}-1.0092 \\
\mathrm{R}^{2}=0.6246\end{array}$ & 0.6286 & $\begin{array}{l}\mathrm{y}=5.4117 \mathrm{x}-3.7435 \\
\mathrm{R}^{2}=0.3952\end{array}$ \\
\hline 2007 & 0.8085 & $\begin{array}{l}\mathrm{y}=2.6548 \mathrm{x}-1.1723 \\
\mathrm{R}^{2}=0.6536\end{array}$ & 0.5775 & $\begin{array}{l}\mathrm{y}=5.1315 \mathrm{x}-2.8905 \\
\mathrm{R}^{2}=0.3335\end{array}$ \\
\hline
\end{tabular}

[Here, $\mathrm{R}=$ Correlation, $\mathrm{Rn}=$ Global Integration, $\mathrm{R} 3=$ Local Integration and $\mathrm{R}^{2}=$ Tangent of Slope
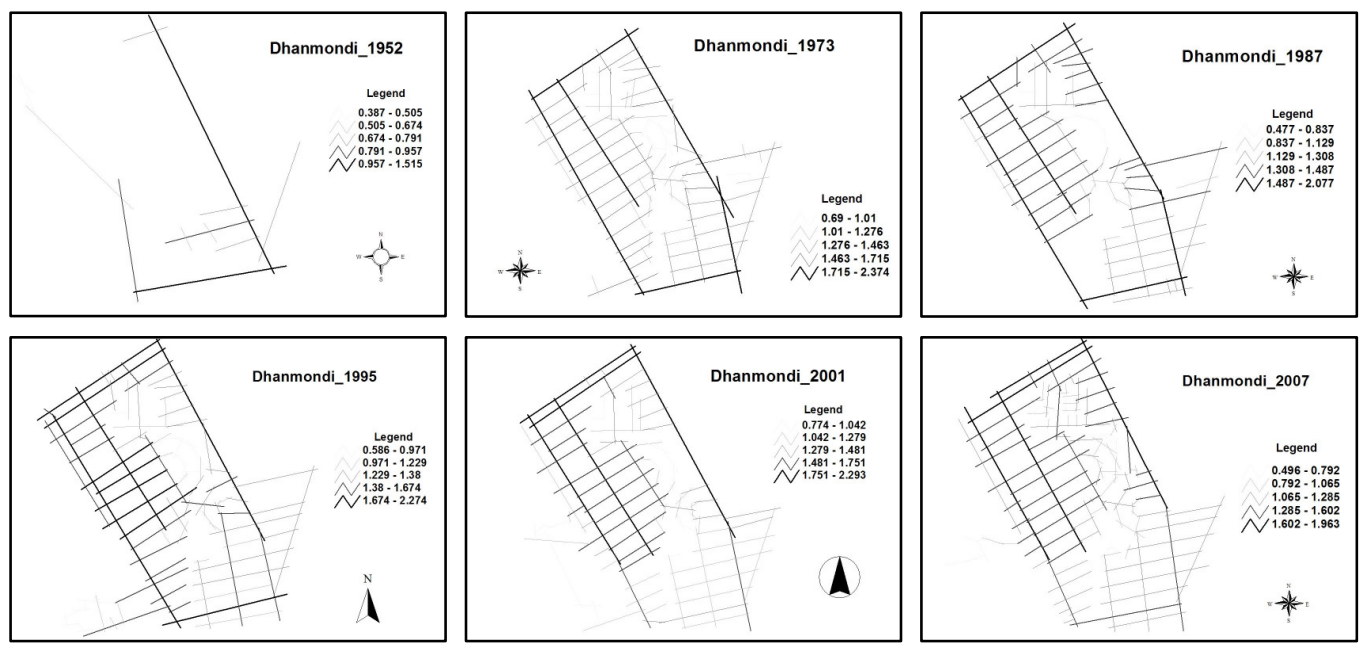

Fig. 3: Global Integration $(\mathrm{R}=\mathrm{n})$ of Ward 49 in Different Time Periods (Not to Scale) 

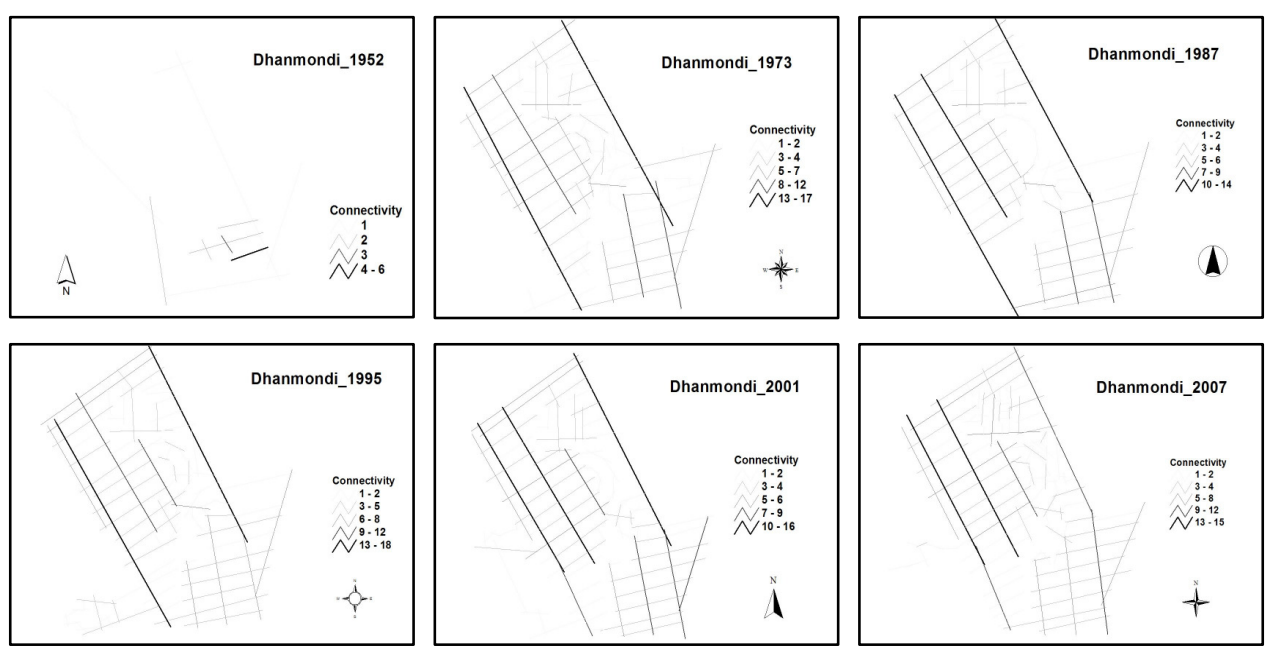

Fig. 4: Connectivity (CN) of Ward 49 in Different Time Periods (Not to Scale)

Being a planned residential area, the syntactic measures are showing quite unchanged and high values in all phases. Only in case of 1952, some abrupt values are found because in that time period, the area was not developed rather it was almost open field. The higher values indicate that the street network is highly connective among each other.

\section{Ward 72: A Detailed Morphological Analysis}

Ward 72 is located in old Dhaka. It is in one of the oldest historical core of Dhaka City (Geddes, 1917:25). This area exists from the Pre-Mughal period. The city area consists of a few market centers like Shankhari Bazar, Tanti Bazar, and a few localities of other craftsmen and businessmen that were also existed in the Pre-Mughal period. Ward 72 is located in Kotwali Thana (Figure 05). Kotwali Thana Area is considered as old Dhaka. Many administrative establishments including Dhaka City Corporation, Police Headquarters, Bangladesh Fire Service, Lawyer Court and Judge Court are located surrounding this Ward. Thana is the unit for Police administration in urban areas.
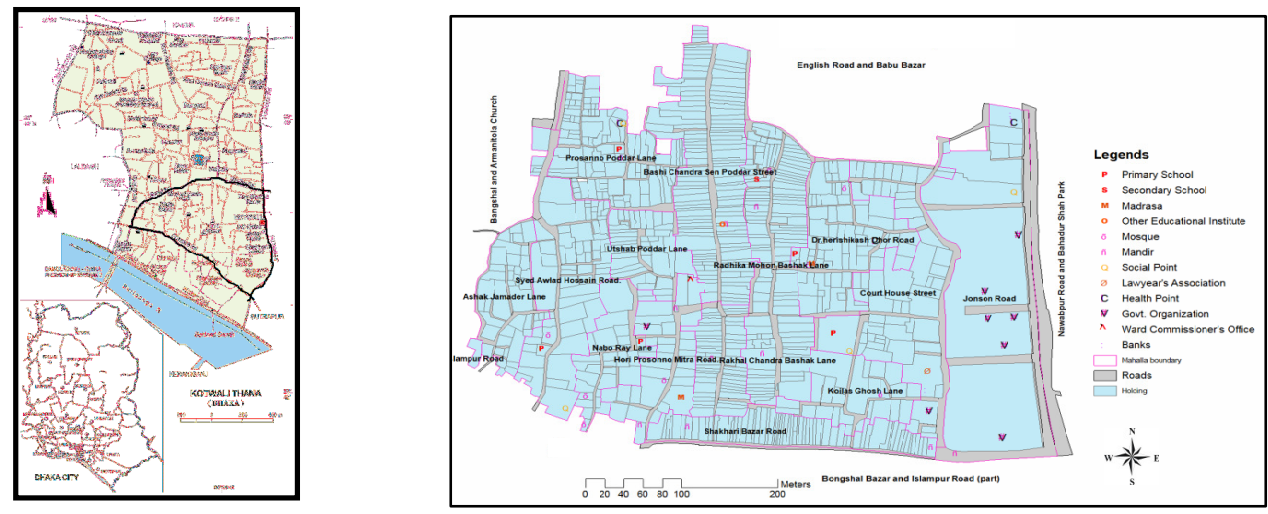

Source: http://www.bangladesh.gov.bd/maps/images/dhaka/DhakaKotwaliT.gif and DCC, 2006

Fig. 5: Map of Kotwali Thana and Ward 72 

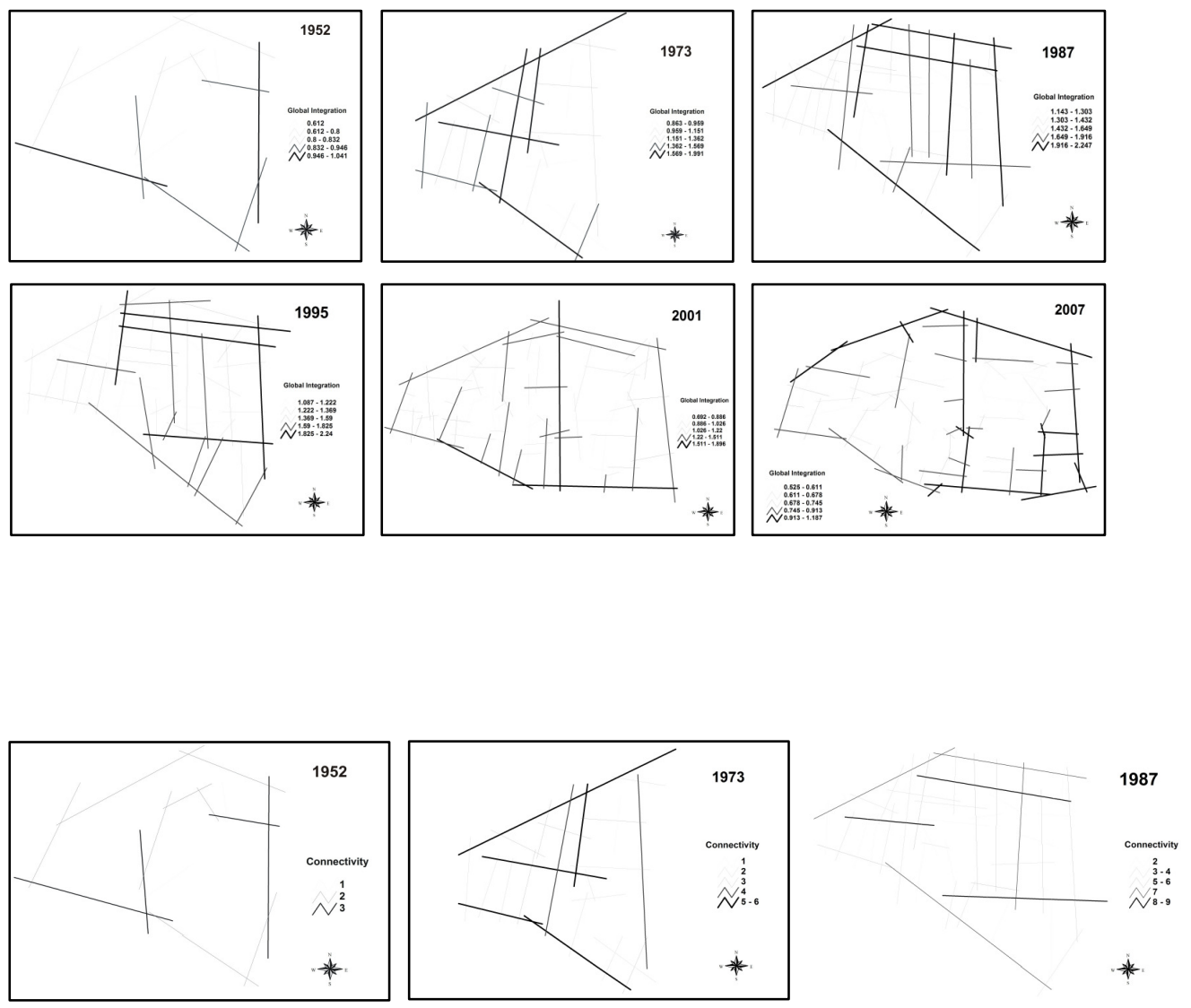
ERROR: undefined

OFFENDING COMMAND: $f ‘ \sim$

STACK : 